\title{
Philosophical Technologies in Educational Process in the XXI Century
}

\author{
Vladimir Tsvyk \\ Department of Ethics \\ Faculty of Humanities and Social sciences \\ Peoples' Friendship University of Russia \\ Moscow, Russia \\ E-mail: tsvyk_va@pfur.ru
}

\author{
Irina Ts vyk \\ Department of Philosophy \\ Moscow Aviation Institute \\ National Research University \\ Moscow, Russia \\ E-mail: tsvykirina@mail.ru
}

\begin{abstract}
The article is dedicated to the role of philosophical technologies in modern educational process. Features of educational process in the XXI century are considered, the aiming an education system on the formation of harmoniously developed identity of the professional is stated. The conclusion that modern education as the original formation of the personality is impossible without wide use of the philosophical technologies personifying intellectual and cultural experience of mankind and providing transfer of this experience to new generations is reached.
\end{abstract}

Keywords-philosophy; philosophical technologies; education; educational process; personality; professionalism

\section{INTRODUCTION}

One of the actual problems of a modern system of education is how to define the status of philosophical disciplines in educational process. Today philosophy is studied practically in all higher education institutions of Russia, irrespective of their specialization. This fact, in our opinion, is caused by the important role that philosophical technologies play in formation of social and personal qualities of future professionals. Philosophy is the highest form of wisdom, formation of mentality which is engaged in the critical and enlightening activity, the form of initiating cultural innovations. In the history of human thought attempts to connect philosophy to religion, science, or art have occurred quite repeatedly. However, with all the absorption into these mental forms, philosophy is independent and unique entity which has the perspective, the purposes and tasks. With that philosophy is the real welfare practice uniting life experience of the philosopher and real work of human mind on development of surrounding reality.

Founders of philosophy created all necessary in order that wise men became philosophers, and philosophical wisdom was the norm for ordinary people consciousness. Generalization of their ideas allowed to synthesize philosophical technologies which are available to people with sensible mind as the best instrument of labor and the sharpest weapon at the solution of all problems, including identification of all phenomena. The philosophy as a live and mighty intellectual and spiritual stream in consciousness of the person is capable to act as the system of the technologies of reality development directed on opening new knowledge and formation of effective cogitative strategy.

The role and value of philosophical technologies immeasurably increases in modern conditions of prompt complication of social, spiritual, cultural life of society, intellectualization of activity and work. It is caused by dynamism and the scale of tasks which the mankind in process of the development meets. An increase of the integrity of the world and an increase of interrelation of various aspects of life assumes the introduction to a daily turn of information on difficult processes of global character. To be guided adequately and furthermore consciously to participate in these processes, the personality has to be comprehensively developed and well educated. At all times the philosophy formed strategy of thinking and decisionmaking of creatively clever persons. We can claim with confidence that in the modern world philosophical technologies are urged to play the leading role in formation of personality's professionalism.

\section{PROFESSIONALISM OF THE PERSONALITY AS PURPOSE OF EDUCATIONAL PROCESS}

Objective conditions of modern civilization development demand reorientation of the society to professionalism: in all spheres of work without exception the human factor becomes leading point. Society interest in professionals, i.e. the workers not only with high professional skills, but also with analytical, creative skills, steady world outlook basis and humanistic valuable reference points is growing. Professionalism is becoming one of the main values of modern youth. By results of sociological research of students in 2013 professionalism and skill wins first place $(95 \%$ responded) among reference, i.e. desirable qualities of the Russian students [1].

The present stage of social development is characterized by high extent of professionalizing society, by complication of professional structure of society, and by increase of public requirements to representatives of various professions. The realities of modern life which are characterized by the accelerated rates of changes compel to look for new approaches to the analysis of the significant social phenomena and qualities of the personality. 
The highest characteristic of professional development of the personality providing its ability to the productive, constructive, creative professional labor is the professionalism as a compliance of knowledge, abilities, skills, as well as all the valuable system of the person to what occurs in concrete area of professional practice and specialization. Professionalism of the personality is based on compliance of a wide range of personal professional qualities of the expert (skills, abilities, knowledge, values, ideals) to the level of public expectations from this profession [2. P. 255].

The most important manifestation of professionalism as highest step of professionalizing of the personality is an ability to free creative activity, to a practical reorganization of the world. This ability in great degree is caused by formation and development of intellectual professional culture of the personality as one's abilities to professional growth, to receiving new knowledge, to the solution of complex professional challenges in the conditions of dynamically developing society.

At the heart of professional and social development of the personality lies the knowledge. With knowledge people seize the object of the creative activity and transform it ideally. In 1971 D. Bell claimed: "The concept "postindustrial society" places emphasis on the central role of theoretical knowledge as the axis round which the new technology, economic growth and new stratification of society" is built [3]. Massive sociological researches steadily show the impact of education level on psychological and social characteristics of the personality. According to experts' forecasts, intellectualization of work becomes the main factor of the global competition in the XXI century. In the developed countries $70-85 \%$ of a GDP growth is due to the share of new knowledge embodied in technologies, equipment, educated staff, and the organization of production.

Introduction of new technologies, informatization and automation of production are making such changes to professional work which implementation requires the development of multilateral and universal abilities. Within post-industrial society "spesializm" appears to be replaced by universalism and professionalism. Professionalism of the personality is inseparably linked with education. Formation and forming the identity of the professional, mainly, happens at institute of the higher education which special role is to turn universal values into system of spiritual professional qualities of the personality.

During primary professionalizing through the system of the general and professional education the person acquires knowledge and develops his intelligence. Ability of the person to work depends on the level and quality of the general and professional knowledge. These indicators determine the intellectual and professional potential of the personality. The knowledge of laws of development of the nature and society, a broad outlook in accord with vocational training are the basis for formation of professional potential of the individual.
The intellectual outlook which is formed in the person from the first steps of his life, especially in the course of education, creates a basis for creative, originally professional activity. However, it isn't necessary to put the level of general education training of the personality and one's professionalism into direct dependence. Education lays the foundation of professional thinking, forms a rational component of professional consciousness of the personality and by that creates an intellectual basis of professionalism. But the sum of a certain knowledge, as well as the existence of necessary professional skills and abilities in itself don't guarantee professionalism. Professionalism is formed, eventually, by all way of life of the person, it seriously depends on personal qualities of the personality.

The modern professional has to be able to think creatively, independently to solve complex problems in a concrete kind of activity. Besides, he needs to adapt constantly for new knowledge and technologies to improve the qualification. Continuous education, systematic professional development, professional and personal improvement becomes an indispensable condition of successful work of any person occupied with professional activity.

\section{FeATURES OF EDUCATIONAL PROCESS IN THE XXI CENTURY}

In the conditions of the modern modernized Russian society priorities of a public and personal choice were radically replaced in the system of Russian education. Education is even more often considered not simply as the process of acquiring systematized knowledge by the person, but as the preparation and inclusion of the individual into various spheres of activity of society today. In this context the definition of substantial borders of the concept "education" which ethical aspects are defined in each case owing to its polysemy is very essential. Education is: (1) the social institute, which main function consists in preparation and involving the individual in various spheres of the activity of a society; (2) a set of the systematized knowledge, abilities, skills (especially professional) acquired by the individual (independently or in the course of training in special educational institutions); (3) the process of assimilating knowledge, i.e. training and education; (4) the level of education of the individual with versatile knowledge and notable for a high degree of culture; (5) culture of the society, people as the level of civilization of the country [4. P. 9-10]. Nevertheless, in all listed cases the defining point is not the amount of education only in its educating meaning that matters, but mainly "education", "creation" of the personality which is most important.

The education system is traditionally allocated as the institute of socialization of the personality in general. Professional development of the personality today, in the XXI century, acts as an essential component of socialization. As the most important agent of professional development of the personality, institute of education possesses a number of specific features. Firstly, it is distinctly expressed purposeful nature of influence: for any form of education (secondary, special, professional) it is characteristic the accurate 
explication of the purposes is formation of the personality, formation of knowledge, skills and abilities, familiarizing the person with culture, preparation to work. In the context of the humanistic paradigm relying on the developing approach among the other purposes of education the priority place is taken by disclosure of individual creative potential of the personality [5. P. 210]. Secondly, for any education system orientation to ideal model is characteristic: educational and educational influence in it assumes existence of some ideal sample (expressed in the sum of abilities and knowledge and in qualities of the personality) which needs to be received "at the exit". Thirdly, any educational institute bears in itself the rational criteria of an assessment of the activity understood, as a rule, through a degree of compliance of what turned out "at the exit" to the declared ideal sample.

Specifics of a modern education system consist in strengthening of a humanistic component. At educational institutes of the XXI century the accent is transferred from education and training to the education capable to create the personality, whose values meet vital needs of modern times. Thus education is understood as the creation of such conditions which are capable to provide disclosure of inclinations and abilities of the personality [6. P. 8]. The most important purpose of functioning of educational systems is training the personality for realization of the social functions.

In the context of a humanistic paradigm of the formation of a problem of scientific education, vocational training in relation to the purpose of development of the personality have to be considered as the means providing achievement of the last. The education system is responsible for preparation to independent life and professional activity of future experts and satisfies their individual educational requirements.

Development and intensification of production, scientific and technical progress, change of the nature of professional activity demand from the professional's continuous replenishment of knowledge both in the sphere of production of goods, and in spiritual area. Recently as the most important function of an education system formation of intellectual culture of the personality allocate is allocated, i.e. in the course of education people have to gain not simply some sum of knowledge but learn to think independently and non-standard, to create and to take responsibility for the made decisions [7. P. 27].

One of the most important functions of education is the disclosure and development of natural potential abilities (and opportunities) of the person to the continuous, advancing a basic state, active increment of knowledge, to the development on this basis as individuals to the purposeful, innovative, predictively focused on the basis of the gained knowledge formation of the environment of the activity with simultaneous increase of individual readiness for dynamic and creative behavioral adaptation in the changing environment conditions including production.

\section{PHILOSOPHICAL KNOWLEDGE IN EDUCATIONAL PROCESS}

Creation in modern Russian society the system of continuous education of the person during all his life, the corresponding adjustment and modernization of the general and professional education with preservation of its traditional forms, the humanization, humanitarization and "socialization" of education are necessary steps on the way to formation of a professionally competent personality - the member of the XXI century, the professional. Expansion of a fundamental component of the higher education not only as a basis for complete perception of the world, but also as an indispensable condition for the subsequent lifelong education becomes the most important direction of reforming of the Russian higher school.

Quite often in literature and in ordinary perception professionalism is understood only as mastering any narrow specialization, prosperity in any one branch of labor and professional activity. Even more often the opinion that that knowledge and abilities which aren't included into the list necessary for mastering a profession (i.e. aren't the center of future professional activity of the personality) is reproduced. So, for example, future physicist doesn't need literature, mathematics doesn't need history, chemistry is not necessary for literary critic, etc. One of the deepest delusions of today's attitude to professionalism based on unilateral and narrow understanding roots in it.

Many researchers of problems of modern Russian professional education note that the vocational higher school doesn't provide the sufficient width and depth of professional education in general. The increasing recognition is gained by understanding according to which, first of all, it is necessary to master forms, ways of action, but not theories, the principles and methods. Moreover, the tendency to allocating the training focused not on formation of the personality but on training the professional functionary with operational thinking takes place. It is obvious that the concept "professional functionary" is used here in the narrow value, as the "expert" who is a partially developed worker, possessing the professional knowledge and skills allowing him to carry out concrete technological operations but insufficient for full and creative professional activity.

In modern research literature the real distortion towards narrow special preparation is stated. The tendency on profiling the general scientific disciplines, removal of theoretical material to the level of tool practice was fixed. Many teachers of humanitarian disciplines of the higher school of Russia faced this process in the early nineties when "non-core" subjects were literally expelled, the number of classes were reduced, many courses were transferred to the category of the optional. Unfortunately, this tendency isn't still overcome. This problem is characteristic not only for the Russian higher education. "Specialization" of professional education, the student's orientation on receiving highly specialized knowledge to the detriment of personal and world outlook development has generated a very actual problem of the "partial" personality today in many industrially developed countries. In the majority of 
industrially developed countries of the world the emphasis is placed on vocational education to the detriment of complete vision of the world. A.N. Whitehead noted that it concerns England as well: "Now our education combines detailed studying of limited number of abstractions with superficial studying of a large number of abstractions. We suffer from a bookishness in our school routine" [8. P. 260-261]. In this situation the problem of a ratio of vocational and common cultural education is significantly actualized as the vocational education directed on studying the concrete phenomena acts as a basis for technological development in a broad sense of this word whereas the general education forms a kernel of world outlook culture of the personality.

The systematic analysis of sources and bases of this problem testifies that it took roots in the European culture during an era of industrial society and was connected with formation of a new industrial and mass person, a narrowly professional worker. Industrial and technological development of the developed countries, their achievements in the field of material welfare and development of the world were closely connected with the concentration of attention on studying details, with accumulation of knowledge of concrete processes, with the narrow professional specialization understood as the existence of special skills. Receiving vocational education, professionally mastering any certain type of work becomes socially favorable and socially significant. Vocational education in these conditions turns into priority value. "Thereby, specializing, education not only submits to requirements of production, but also in a certain measure this process influences education specialization, formation of public requirements and values" [9. P. 11].

Education specialization in itself isn't a threat to all-round development of the personality, on the contrary, vocational education represents a necessary and significant component of primary professionalizing and is the most important stage of transformation of the person into the professional. The problem is that sometimes special knowledge appears the most socially significant and force out other universal values from the center of cultural space. Moral, esthetic values become minor and submit to special knowledge, and social arts education of the personality appears superfluous.

According to N. Chebyshev and V. Kagan, a phenomenon of "discontinuity" of thinking: "Students can't use scientific knowledge as the base of motivation, deep understanding of the activity. Students don't learn to use the potential of fundamental disciplines for the complete, system solution of informative and professional tasks" [10. P. 50] which turns out to be the consequence of excessive specialization of professional education. Similar processes happen practically in all countries of an era of an industrial civilization.

Speaking at the conference devoted to humanitarian training of students of non-humanitarian colleges, Rector of Moscow Institute of Physics and Technology N. V. Karlov noted: "Young people, 17-18-year-old, after three years of hard work in physics, mathematics, become practically professionals ... they understand an essence, the nature of things, they understand what mathematics is and what mathematical model means, they skin and they have a gut feeling and are deeply convinced that any science can be reduced to a set of common sense and mathematics ... But living in the world surrounding them they immediately gain tendency to overturn the high professional knowledge of the nature of things onto social, human, interpersonal. But social it is much more difficult than naturally scientific ... They also don't know it, don't understand" [11. P. 14].

The similar situation is inherent in the industrial model of a civilization in general. The reduction of social and humanitarian to natural science has become a world outlook installation of the European culture under the influence of natural sciences, especially classical mechanics, and then physical science. An essential lack of educational systems of the industrial countries is also underestimation of a moral component of education, secondariness of the moral origin in relation to such values as the reason, the right, economy. The development of the industry, mass production demanding training specific experts led to a deindividualization and to a dehumanization of professional education, to the replacement of spiritual components to the periphery of the personal beginning or to their submission to tightly pragmatical purposes. Meanwhile as far back as M. Sheler noted: "Education is not "educational preparation for something", for a profession, specialty, for any productivity, and especially education exists not for the sake of such educational preparation" [12. P. 31].

The new post-industrial, information civilization demands new model of the general and professional education training not the mass and standardized people but creatively conceiving, capable for innovation and continuous improvement comprehensively developed persons. In recent years the understanding of need of common cultural and humanitarian training of specialists in the field of technical science and natural-science knowledge is growing. The remarkable fact is that scientists - mathematicians, physicists, etc. - even more often start speaking about the need to have not only special, but also liberal education, some state the deep belief that the XXI century will be a century of the humanities (N. N. Moiseev). Many authors also note that with the complication of engineering work the range of the factors determining professionalism level in engineering activity has sharply extended. Scientific and technical creativity, characteristic for engineering activity, is impossible without high level of development of the general and professional intelligence, creativity of the personality and the developed imagination. Besides, readiness for engineering activity assumes deep awareness of the public importance of engineering work, ability to learning ability, ability to carry out professional communication and interaction, a high level of the development of the general culture. All this is provided fully by philosophy.

The humanities always played an important role in the development of the dominating cultural values and meanings. They unlike natural sciences are focused on knowledge of integrity of human spirit, unity of rational and irrational in the person [13. P. 107]. It is the humanities, and philosophy, first of all, which promote the reduction of distance between 
various cultures which also makes the important purpose of modern education.

\section{CONCLUSION}

Philosophy, being a rational form of public consciousness, acts as a basis of formation of the philosophical culture directed on formation of scientific outlook, analytical thinking, ability of intelligence to the fullest transfer and perception of information and selfreflection [14. P. 34]. Whatever different was the philosophy - materialistic or idealistic, rational or irrational, etc. showing a commonness of intellectual life, carrying out world outlook, methodological and humanistic functions, it promotes the emergence of new opportunities for a dialogue between various forms of cognitive activity differing in the valuable preferences.

In the modern world in which the increasing role is played not only by vertical cuts of professional work, but also by broad horizontal welfare communications of experts, the professional can't take place without mastering the main welfare world outlook values, wide "experience of society". The concept of professionalism, thus, joins a harmonious combination of labor skills and abilities to the wide world outlook horizon, ability to assess a situation and to coordinate own professional tasks to social requirements of time. In this connection, professionalism becomes not only an important component of labor and professional activity of the person, but also one of the main characteristics of moral shape of the human person. The perception of the world through a prism of the good and evil, his moral experience can be also referred to philosophical technologies.

Philosophical technologies are a part of methodological provision not only for scientific researches, but also for many types of professional activity, they are necessary for theoretical constructions and applied researches as they are the integral component of fundamental education. The modern professional has to possess qualities of a spiritually rich person who not only functionally becomes the member of a certain group, but in himself meets the special requirements as any progress relies not only on the professional level of experts, but also on their general culture. Therefore, modern education as the original formation of the personality is impossible without a wide use of philosophical technologies personifying intellectual and cultural experience of the mankind and providing transfer of this experience to new generations.

\section{REFERENCES}

[1] Tikhonova N.E. Social structure of Russia: theories and reality. - M, 2014. $-408 \mathrm{p}$

[2] Tsvyk V.A. Professionalism: Experience in social and philosophical analysis. - M.: Publishing the Peoples' Friendship University, 2004. $289 \mathrm{p}$.

[3] Bell D. The Post-Industrial Society: The Evolution of an Idea. The Coming of Post-Industrial Society, Social Forecasting. - New York, 1973.
[4] Tsvyk V.A. Higher school ethics (at the example of Peoples' Friendship University of Russia)// Bulletin of Peoples' Friendship University of Russia. Series: Philosophy. - 2016. - №3. - P. 9-19.

[5] Filippov V.M. Internationalization of the higher education: main tendencies, problems and prospects//Bulletin of the Russian university of friendship of the people. International relations. -2015 . - № 3. - P. 203-212.

[6] Tsvyk V., Tsvyk I. Teaching Ethics Courses in the System of Higher Education in Russia: Problems and Prospects //Proceedings of the 2016 International Conference on Contemporary Education, Social Sciences and Humanities// Advances in Social Science Education and Humanities Research. T. 74. - P. 7-11.

[7] Tsvyk I.V. Teaching ethics in technical colleges: problems and prospects//Bulletin of Peoples' Friendship University of Russia. Series: Philosophy. - 2016. - № 3. - P. 26-34.

[8] Whitehead A.N. Selected texts on philosophy. - M, 1990. -720 p.

[9] Talalova L.N. Integration processes in education: context of contradictions. - M, 2013. $-368 \mathrm{p}$.

[10] Chebyshev N., Kagan V. Therapy of a phenomenon of "discontinuity" of thinking//the Higher education in Russia. - 1999. № 1. - P. 48-52.

[11] Karlov N.V. Synthesis of humanitarian and naturalscience//Humanitarian training of students of not liberal arts colleges and experts of a humanitarian profile. Materials of the All-Russian conference on April 2-3, 1992 - M., 1992. - P. 14-17.

[12] Sheler M. Selected texts - M, 1994. - $413 \mathrm{p}$.

[13] Kulikova T.V. "Uselessness" and need of philosophical knowledge// Integration of education. - 2004. - № 1. - P. 106-111.

[14] Ilyina J.A. Place of philosophy in educational process// Symbol of a science. - 2016. - № 2. - P. 33-35. 